\title{
Primary signet-ring cell carcinoma of the lung treated with crizotinib: A case report
}

\author{
YUE-QIN HAO ${ }^{1}$, HUA-PING TANG ${ }^{1}$ and HONG-YUN LIU ${ }^{2}$ \\ Departments of ${ }^{1}$ Respiratory Medicine and ${ }^{2}$ Pathology, Qingdao Municipal Hospital, Qingdao, Shandong 266600, P.R. China
}

Received April 15, 2014; Accepted January 8, 2015

DOI: $10.3892 / \mathrm{ol} .2015 .3003$

\begin{abstract}
Primary signet-ring cell adenocarcinoma (SRCA) of the lung is an extremely rare subtype of lung adenocarcinoma with a poor prognosis. The presence of an SRC component is considered to be a prominent clinicopathological characteristic of EML4-ALK-positive non-small cell lung cancer (NSCLC). Crizotinib, an anaplastic lymphoma kinase inhibitor, has been approved for the treatment of EML4-ALK NSCLC by previous studies, but its effect on SRCA, an extremely rare subtype of lung adenocarcinoma, has yet to be elucidated. Therefore, the present study aimed to evaluate the clinical response of SRCA to crizotinib, and examine the potential use of crizotinib as a treatment for the carcinoma. A 43-year-old male was admitted to the Qingdao Municipal Hospital (Qingdao, China) with dyspnea. Chest computed tomography $(\mathrm{CT})$ revealed a mass in the middle lobe of the right lung. Transbronchial lung biopsies revealed the presence of SRCA (70\%) mixed with poorly-differentiated adenocarcinoma (30\%). Immunohistochemically, the SRCA cells were positive for cytokeratin (CK)7 and thyroid transcription factor-1, and negative for CK20. An inversion of the EML4-ALK gene was detected by fluorescence in situ hybridization and crizotinib was injected by nasogastric tube. The patient was highly responsive to crizotinib. The symptoms of dyspnea were relieved and the volumes of pericardial and pleural effusion were gradually reduced. A CT scan revealed lung tumor regression. The overall response was a partial response. Therefore, crizotinib exists an attractive therapeutic option for patients with SRCA. However, in the present study, acquired drug resistance to crizotinib developed after only one month of treatment. It would consequently be valuable to investigate the mechanisms underlying acquired crizotinib resistance in future studies.
\end{abstract}

Correspondence to: Professor Hua-Ping Tang, Department of Respiratory Medicine, Qingdao Municipal Hospital, 5 Donghai Zhong Road, Qingdao, Shandong 266600, P.R. China E-mail: 15726259705@163.com

Key words: crizotinib, primary signet-ring cell adenocarcinoma, EML4-ALK

\section{Introduction}

The majority of cases of signet-ring cell adenocarcinoma (SRCA) of the lung originate from the gastrointestinal tract. Primary SRCA of the lung, originally described in 1989 by Kish et al (1), is an extremely rare subtype of adenocarcinoma, which confers a poor prognosis compared with other subtypes of adenocarcinoma (2). Previous studies have identified that a high proportion of EML4-ALK-positive non-small cell lung cancer (NSCLC) tumors in North America possess SRC components $(3,4)$. Therefore, the presence of an SRC component may be an important clinicopathological feature of EML4-ALK-positive NSCLC. In 2007, the discovery of EML4-ALK, a lung cancer-induced fusion gene, was considered to be an advance in the understanding of NSCLC (5). Crizotinib, which was approved by the Food and Drug Administration on August 26, 2011, is recommended for patients who carry the EML4-ALK gene rearrangement (6). The development of an anaplastic lymphoma kinase (ALK) protein inhibitor with approved clinical activity has led to an understanding of the clinicopathological features and survival rates of patients with EML4-ALK NSCLC $(4,7)$. To the best of our knowledge, the present study is the first to describe a case of primary SRCA of the lung with an EML4-ALK gene rearrangement. The clinical response to crizotinib was monitored throughout the therapeutic process.

\section{Case report}

A 43-year-old male, who was a non-smoker, was admitted to the Qingdao Municipal Hospital (Qingdao, China) on June 27, 2012, with a cough and dyspnea that had been apparent for one week. Chest computed tomography (CT) revealed an irregularly-shaped mass in the middle lobe of the right lung. Bilateral pleural and pericardial effusion was also observed (Fig. 1). The levels of the tumor markers, cytokeratin (CK)-19 fragment 21-1, neuron-specific enolase, carcinoembryonic antigen and cancer antigen series, were within the normal ranges. Metastatic tumors were detected in the bone by positron emission tomography/CT. The pathological findings of the transbronchial lung biopsies revealed the presence of SRCA (70\%) mixed with poorly-differentiated adenocarcinoma cells (30\%) (Fig. 2). Immunohistochemical analysis was performed in order to differentiate between primary and metastatic SRCA. The results revealed that the SRCA cells 


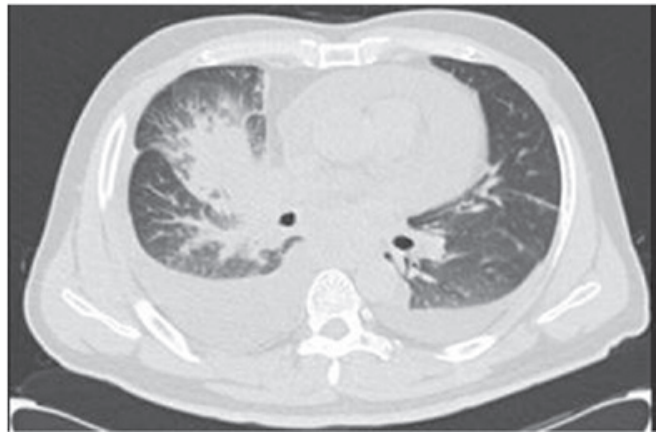

Figure 1. Chest computed tomography revealing an irregularly-shaped tumor in the middle lobe of the right lung. Bilateral pleural and pericardial effusion was also observed.

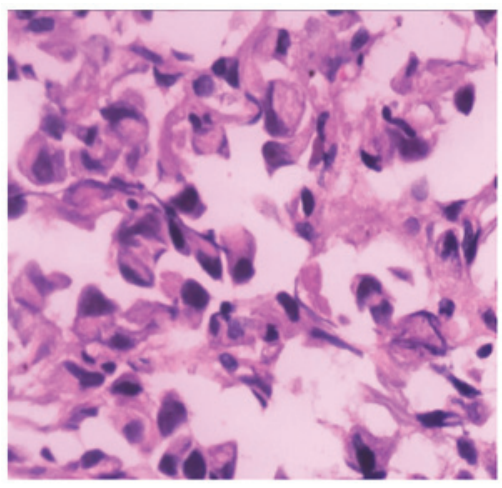

Figure 2. Biopsy image revealing features typical of signet-ring cell adenocarcinoma (hematoxylin and eosin stain; magnification, $\mathrm{x} 400$ ).

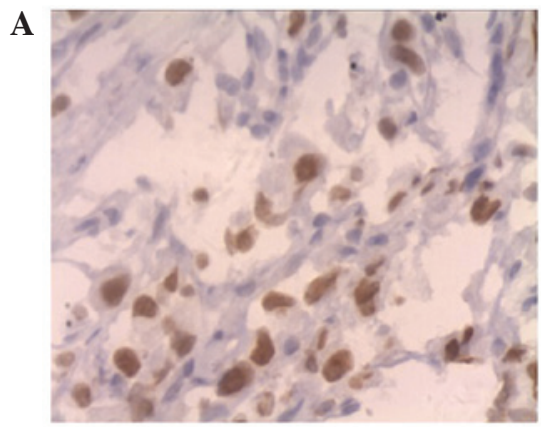

B

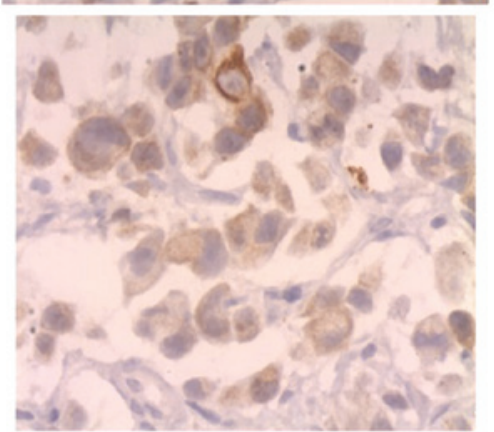

Figure 3. Immunohistochemical analysis revealing tumor cells positive for (A) thyroid transciption factor-1 and (B) cytokeratin 7 immunostaining (magnification, $\mathrm{x} 400$ )

were positive for thyroid transcription factor-1 and CK7, but negative for CK20 (Figs. 3 and 4). Upper and lower gastrointestinal endoscopy revealed the absence of further tumors.

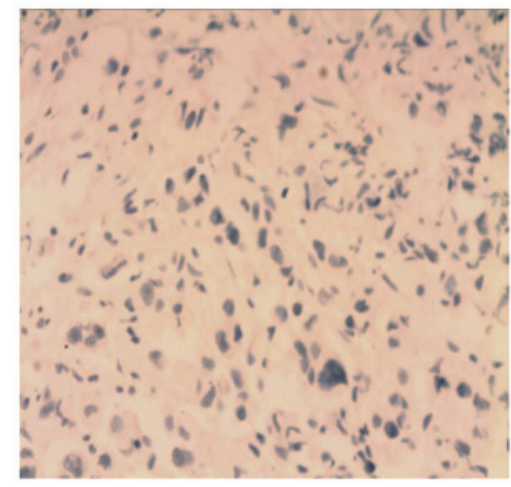

Figure 4. Immunohistochemical analysis revealing tumor cells negative for cytokeratin 20 immunostaining (magnification, x200).

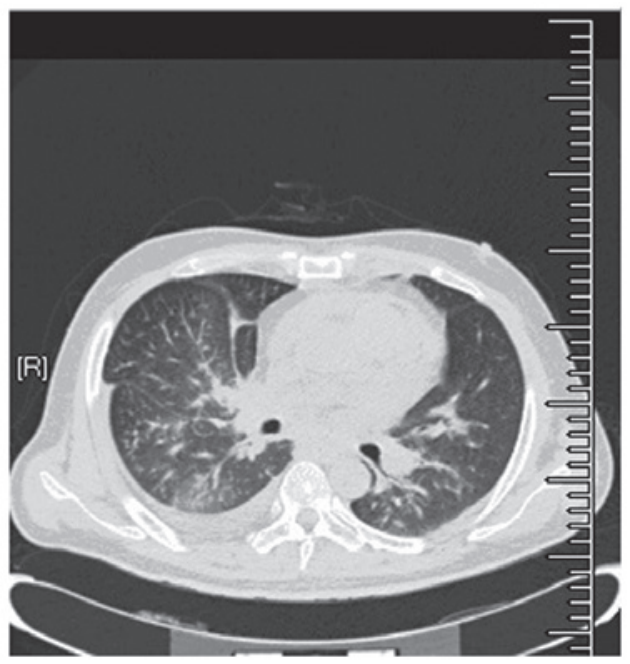

Figure 5. Chest computed tomography revealing lung tumor regression following treatment. A decrease in the volume of pericardial and pleural effusion effusion was also observed.

Consequently, a pathological diagnosis of stage IV SRCA of the lung was established with a tumor-node-metastasis classification of T4N3M1. Upon admission to the Qingdao Municipal Hospital, the patient experienced rapid clinical deterioration. Massive pleural and pericardial effusion was detected by type-B ultrasonic examination. A clinical cytological examination revealed the presence of malignant cells in the pleural and pericardial effusion. Immediate pericardiocentesis and pleurocentesis were required due to the onset of cardiac tamponade. However, as the effusion developed rapidly, a pericardiotomy was performed for continued drainage with a catheter. On July 13, 2012, the patient underwent tracheal intubation and mechanical ventilation for respiratory support, and was transferred to the intensive care unit (ICU). During this period, the tumor was analyzed for mutations in the epidermal growth factor receptor, but the result was negative. Inversion of the EML4-ALK gene was then detected by fluorescence in situ hybridization from a sample sent to the Peking Union Medical College Hospital (Beijing, China). On July 20, 2012, it was established that the tumor was ALK-positive. By that time, the patient had been transferred to the ICU and had received mechanical ventilation for seven days. Crizotinib $(250 \mathrm{mg})$ was therefore administered twice daily via 
a nasogastric tube for three months. The following month, the condition of the patient had improved. The symptom of dyspnea was relieved and the volume of pericardial and pleural effusion was gradually reduced. A CT scan revealed lung tumor regression (Fig. 5). As a result, the pericardial catheter and nasogastric and tracheal tubes were successfully removed. However, one month after removal, the patient began to deteriorate, following three months the patient succumbed to the disease.

Written informed consent was obtained from the patient for publication of this case study and any accompanying images.

\section{Discussion}

The identification of the EML4-ALK gene translocation in cases of NSCLC, and the development of an approved ALK inhibitor has led to an understanding of the clinicopathological characteristics and prognosis of EML4-ALK NSCLC patients. EML4-ALK has become a novel therapeutic target for the treatment of NSCLC. ALK inhibitors have presented an opportunity for the individualized treatment of lung cancers (8) and provided an alternative therapeutic approach for those patients intolerant to chemotherapy and radiation therapy. In the last two decades, cases of primary SRCA have failed to respond to traditional chemotherapy and radiation therapy, and therefore, the condition was considered to have a generally poor prognosis. The significance of SRCA was not truly appreciated until the publication of recent study results, which linked SRC to EML4-ALK NSCLC $(9,10)$. In early clinical trials, the ALK inhibitor, crizotinib, demonstrated a high response rate in patients with ALK-positive NSCLC $(11,12)$. Despite this, a number of patients enrolled in the trials developed resistance to the drug (13). In fact, acquired drug resistance is a problem encountered for a considerable number of targeted cancer drugs. In the present study, the patient was, at first, highly responsive to crizotinib. However, subsequent to just one month, resistance to crizotinib developed and the condition of the patient began to deteriorate. After three months, the patient succumbed to the disease. Cases of acquired drug resistance to targeted treatments following such a short duration are generally rare. It remains unclear as to whether such resistance is specific to primary SRCA of the lung as a rare subtype, or whether crizotinib is responsible for generating such extensive drug resistance. Therefore, it remains important to continue to investigate the survival outcomes of NSCLC patients with an EML4-ALK translocation who are treated with crizotinib, particularly those with SRCA.

Crizotinib is an attractive option for the treatment of SRCA. The present study described a radiological and symptomatic partial response to first-line crizotinib therapy in a patient with advanced primary SRCA of the lung. However, as acquired drug resistance developed after just one month of treatment, it would be valuable to investigate the mechanisms that underlie crizotinib resistance in future studies, in order to establish methods to improve the treatment.

\section{References}

1. Kish JK, Ro JY, Ayala AG and McMurtrey MJ: Primary mucinous adenocarcinoma of the lung with signet-ring cells: a histochemical comparison with signet-ring cell carcinomas of other sites. Hum Pathol 20: 1097-1102, 1989.

2. Iwasaki T, Ohta M, Lefor AT and Kawahara K: Signet-ring cell carcinoma component in primary lung adenocarcinoma: potential prognostic factor. Histopathology 52: 639-640, 2008.

3. Shaw AT, Yeap BY, Mino-Kenudson M, Digumarthy SR, Costa DB, Heist RS, Solomon B, Stubbs H, Admane S, McDermott U, Settleman J, Kobayashi S, Mark EJ, Rodig SJ, Chirieac LR, Kwak EL, Lynch TJ and Iafrate AJ: Clinical features and outcome of patients with non-small-cell lung cancer who harbor EML4-ALK. J Clin Oncol 27: 4247-4253, 2009.

4. Rodig SJ, Mino-Kenudson M, Dacic S, Yeap BY, Shaw A, Barletta JA, Stubbs H, Law K, Lindeman N, Mark E, Janne PA, Lynch T, Johnson BE, Iafrate AJ and Chirieac LR: Unique clinicopathologic features characterize ALK-rearranged lung adenocarcinoma in the western population. Clin Cancer Res 15: 5216-5223, 2009.

5. Soda M, Choi YL, Enomoto M, et al: Identification of the transforming EML4-ALK fusion gene in non-small-cell lung cancer. Nature 448: 561-566, 2007.

6. Doebele RC, Pilling AB, Aisner DL, et al: Mechanisms of resistance to crizotinib in patients with ALK gene rearranged non-small cell lung cancer. Clin Cancer Res 18: 1472-1482, 2012.

7. Kwak EL, Camidge DR, Clark J, et al: Clinical activity observed in a phase I dose escalation trial of an oral c-met and ALK inhibitor, PF-02341066. J Clin Oncol 27 (Suppl): 3509, 2009.

8. Kwak EL, Bang YJ, Camidge DR, Shaw AT, Solomon B, Maki RG, Ou SH, Dezube BJ, Jänne PA, Costa DB, Varella-Garcia M, Kim WH, Lynch TJ, Fidias P, Stubbs H, Engelman JA, Sequist LV, Tan W, Gandhi L, Mino-Kenudson M, Wei GC, Shreeve SM, Ratain MJ, Settleman J, Christensen JG, Haber DA, Wilner K, Salgia R, Shapiro GI, Clark JW and Iafrate AJ: Anaplastic lymphoma kinase inhibition in non-small-cell lung cancer. N Engl J Med 363: 1693-1703, 2010.

9. Tsuta K, Ishii G, Yoh K, Nitadori J, Hasebe T, Nishiwaki Y, Endoh Y, Kodama T, Nagai K and Ochiai A: Primary lung carcinoma with signet-ring cell carcinoma components: clinicopathological analysis of 39 cases. Am J Surg Pathol 28: 868-874, 2004.

10. Ou SH, Ziogas A and Zell JA: Primary signet-ring carcinoma (SRC) of the lung: a population-based epidemiologic study of 262 cases with comparison to adenocarcinoma of the lung. J Thorac Oncol 5: 420-427, 2010.

11. Girard N: Crizotinib in ALK-positive lung cancer. Lancet Oncol 13: 962-963, 2012.

12. Bang YJ: Treatment of ALK-positive non-small cell lung cancer. Arch Pathol Lab Med 136: 1201-1204, 2012.

13. Tanizaki J, Okamoto I, Okabe T, Sakai K, Tanaka K, Hayashi H, Kaneda H, Takezawa K, Kuwata K, Yamaguchi $\mathrm{H}$, et al: Activation of HER family signaling as a mechanism of acquired resistance to ALK inhibitors in EML4-ALK-positive non-small cell lung cancer. Clin Cancer Res 18: 6219-6226, 2012. 